\title{
El concepto de empatía (Einfühlung) en Max Scheler y Edith Stein. Sus alcances religiosos y políticos
}

\author{
ENRIQUE V. MUÑ̃Z PÉREZ* \\ Universidad Católica del Maule (Chile) \\ enmunoz@ucm.cl
}

\section{Resumen}

El objetivo de este artículo es mostrar que Edith Stein, en su tesis de doctorado, pone las bases de una interpretación filosófica religiosa y filosófico política de la "empatía" (Einfüblung), tomando distancia de las investigaciones y críticas de Max Scheler a dicho concepto en el Sympathiebuch. En otras palabras, al entender Edith Stein la empatía como la experiencia del sujeto ajeno y de su vivencia y extenderla no sólo a la relación con los otros seres humanos, sino que también a Dios, pone los fundamentos de un rendimiento filosófico religioso de esta problemática cardinal de la fenomenología que no se encuentra, al menos expuesto de esa manera, en el Sympathiebuch de Scheler. Además, es posible identificar algunas aplicaciones de la empatía al ámbito político que permiten entender la relación entre individuo y comunidad.

Palabras claves: vivencias, empatía, representación, inmersión, síntesis

\section{The concept of empathy (Einfühlung) in Max Scheler and Edith Stein. Their religious and political scope}

\begin{abstract}
The aim of this article is to show that Edith Stein, in her doctoral thesis, establish the groundwork for a philosophical-religious or philosophical-spiritual interpretation of "empathy" (Einfüblung), taking away the research and criticism of Max Scheler to this concept in the Sympathiebuch. In other words, as Edith Stein understands the empathy as the experience of the strangers and extends it not only to the relationship with other human beings, but also to God, it establish the foundations of a philosophical-religious performance of this main problem of phenomenology that is not found, at least exposed in this way, in the Sympathiebuch Scheler. In addition, it is possible to identify some applications of empathy to the political sphere that allow understanding the relationship between individual and community.
\end{abstract}

Key words: experiences, empathy, representation, immersion, synthesis.

\footnotetext{
* Doctor en Filosofía por la Universidad de Friburgo, Alemania. Profesor Adjunto del Departamento de Filosofía de la Facultad de Ciencias Religiosas y Filosóficas de la UCM. Es autor de los libros Der Mensch im Zentrum, aber nicht als Mensch. Zur Konzeption des Menschen in der ontologischen Perspektive Martin Heideggers (2008) y Heidegger y Scheler. Estudios sobre una relación olvidada (2013). Además, cabe mencionar los artículos recientes: "Trascendencia, mundo y libertad en ek entorno de Ser y Tiempo de Martin Heidegger" (2015), y "El aporte de Jakob von Uexküll a Los conceptos fundamentales de la metafisica. Mundo, finitud, soledad (1929-1930) de Martin Heidegger" (2015).
} 


\section{INTRODUCCIÓN ${ }^{1}$}

La tesis de doctorado (Dissertation) de Edith Stein dirigida por Edmund Husserl denominada "Sobre el problema de la empatía" (Zum Problem der Einfüblung), que la santa carmelita defendió el 03 de agosto de 1916 en la Universidad de Friburgo de Brisgovia, Alemania, pero que fue publicada el año siguiente (1917), se constituyó en un objeto de estudio pendiente para mí por algún tiempo. Conocí su existencia en el marco de una investigación sobre la relación entre Martin Heidegger (1889-1976) y Max Scheler (1874-1928) (Muñoz, 2013). En esa ocasión, buscaba determinar el aporte filosófico que Scheler tiene en el pensamiento de Heidegger, fundamentalmente en Sery Tiempo. Para ello, estudié algunos pasajes de una obra poco conocida de Max Scheler denominada Zur Phänomenologie und Theorie der Sympatbiegefüble und von Liebe und Hass (1913), que tiene un anexo muy relevante titulado: "Über den Grund zur Annahme der Existenz des fremden Ich" ${ }^{\prime 2}$ y que constituye la primera versión de un texto posterior de Scheler, bastante más conocido, denominado Esencias y formas de la simpatía (1923). El Sympathiebuch constituye un punto de referencia y de discusión obligado para Edith Stein como lo evidencia, entre otros, el capítulo 6 de su tesis de doctorado denominado " $\$ 6$. Confrontación con la teoría de Scheler sobre la aprehensión de la conciencia ajena." Cabe preguntarse, en consecuencia, ¿cuál es el interés específico de Edith Stein por las investigaciones de Max Scheler en relación con la "empatía" (Einfühlung)? y, en ese mismo sentido, ¿cuál es la actualidad y la ganancia de una discusión de inicios del siglo XX?

Una breve revisión del estado del arte de esta problemática demuestra que existen dos grandes grupos de intérpretes: los de tradición analítica y los de tradición fenomenológica estricta. Dentro de los primeros, destaca sin duda alguna el trabajo de Dan Zahavi que ha puesto en diálogo, por ejemplo, algunos problemas específicos de la psicología social, como la naturaleza de la cognición social con la tradición fenomenológica (Zahavi,

\footnotetext{
1 Este artículo es una versión parcialmente reelaborada de dos ponencias presentadas consecutivamente en el VI Simposio "La ipseidad en Edith Stein" y el VII Simposio "El estado en Edith Stein", ambos eventos organizados por el Centro de Estudios Interdisciplinarios Edith Stein de la Facultad de Teología de la Pontificia Universidad Católica de Chile, el 11, 12 y 13 de agosto de 2015 y el 09, 10 y 11 de agosto de 2016, respectivamente. Agradezco en especial a los profesores Dr. Mariano Crespo S. y Dr. César Lambert O. por sus comentarios y observaciones, y a la profesora Dra. Hermana Anneliese Meis por su cordial invitación.

2 En adelante será citado como Sympathiebuch. Dado que el original se encuentra en alemán, traduciré las citas al español e indicaré en una nota la versión original, para que sea contrastada por el lector especializado.
} 
2010: 285). Zahavi muestra, a partir de la presentación de autores como Husserl, Stein, Scheler o Schutz, que la fenomenología puede ser una alternativa a las teorías analíticas de la simulación. Dentro del grupo de los intérpretes provenientes desde una tradición fenomenológica más pura, un número significativo de trabajos centra su interés, desde la perspectiva scheleriana, principalmente en una de sus obras maduras Esencias y formas de la simpatía (1923) y casi no consideran la primera versión Zur Phänomenologie und Theorie der Sympathiegefüble und von Liebe und Hass (1913). Esto es posible verificarlo en artículos como los de Dermot Moran o Mariano Crespo S. Moran, por ejemplo, reconstruye el problema de la empatía en autores como Lipps, Scheler, Husserl o Stein (Moran, 2004: 269). Por su lado, Crespo, aborda dos visiones de la experiencia ajena: Husserl y Scheler (Crespo, Inédito: 2). Otras aproximaciones interesantes son las que desarollan Jonna Bornemark y Hans Reiner Sepp ${ }^{3}$, aunque la más cercana a mi lectura, la constituye el trabajo Paolo Zordan quien utiliza y trabaja el Sympatbiebuch ${ }^{4}$, lo que al menos en lengua española es casi inexistente ${ }^{5} \mathrm{y}$ que da, a mi juicio, originalidad al presente trabajo.

De esta manera, la hipótesis que quiero sostener en la presente investigación es que Edith Stein, en su tesis de doctorado, pone las bases de una interpretación filosófica religiosa y filosófica política de la "empatía" (Einfüblung), desmarcándose de las investigaciones y críticas de Max Scheler a dicho concepto en el Sympathiebuch. Dicho de otra manera, al entender Edith Stein la empatía como la experiencia del sujeto ajeno y de su vivencia y extenderla no sólo a la relación con los otros seres humanos, sino que también a Dios, pone los fundamentos de un rendimiento filosófico religioso de esta problemática cardinal de la fenomenología que no se encuentra, al menos expuesto de esa manera, en el Sympathiebuch de Scheler. Además, a partir de los estudios sobre la empatía, es posible comprender, a juicio de Stein, de manera distinta la relación política entre individuo y comunidad. Ella plantea la existencia de una corriente de vivencias de la comunidad.

Para sustentar dicha hipótesis, se hace necesario explicar tanto la discusión que lleva a cabo Scheler en el mencionado Sympatbiebuch como Stein

\footnotetext{
3 El texto de Bornnemark busca resaltar el rol que cumplen Max Scheler y Edith Stein en un eventual giro que desarrolla la fenomenología hacia el tema religioso. A su vez, Sepp persigue identificar el lugar que ocupa la filosofía de Edith Stein en el movimiento fenomenológico.

4 Comparto con Zordan, como se verá más adelante, que se hace incompatible la teoría scheleriana del flujo indiferenciado de vivencias. Véase, al respecto, Zordan, 2005: 70 .

5 Hay que rescatar aquí el trabajo de Fernando Infante, que citamos más adelante, que aborda el tema de la empatía estética.
} 
en su tesis de doctorado en filosofía; del mismo modo, hay que aludir a un par de obras de Stein inmediatamente posteriores, esto es, Contribuciones a la fundamentación filosófica de la psicología y de las ciencias del espiritu (1922) y Una investigación sobre el estado (1924). No desarrollaré, porque ya lo hice en otro lugar, el muy interesante contexto histórico filosófico en el que se enmarca la discusión sobre la "empatía" (Einfüblung) (Muñoz, 2011).

De este modo, dividiré el presente artículo en cuatro momentos: (1) La empatía para Max Scheler, (2) La empatía para Edith Stein, (3) Algunos alcances del pensamiento de Stein y (4) Palabras finales.

\section{LA EMPATÍA PARA MAX SCHELER}

La discusión sobre la empatía se encuentra en el "Anexo" (Anhang) del Sympathiebuch de Max Scheler. El Anexo presenta un subtítulo: "Acerca del fundamento de la suposición de la existencia del otro yo" (Über den Grund zur Annahme der Existenz, des fremden (ch). En dicho anexo, Scheler parte de la siguiente constatación: cuando nosotros nos compadecemos, damos por supuesto en ello la existencia de otra esencia. La pregunta de Scheler es, entonces, comprensible: "¿Cómo alcanzamos la suposición de esa existencia?" (Scheler, 1913: 118) ${ }^{6}$. O formulado de otro modo, “¿qué tipo de actos son aquellos en los cuales aquel conocimiento se origina y cuáles datos son aquellos, que nosotros precisamos para tal suposición?” (Scheler, 1913: 118) ${ }^{7}$. Con otras palabras, ¿qué hechos de la conciencia pueden fundar la existencia del otro? Para responder estas interrogantes, Scheler analiza críticamente las teorías de su época que explican tal fenómeno. Ellas son la teoría de las "inferencias por analogía" (Analogieschlïsse) y la teoría de la "empatía" (Einfüblung).

6 "Wie aber kommen wir zu der Annahme dieser Existenz selbst?" (Scheler, 1913: 118).

7 "Welche Arten von Akten sind es, in denen jenes Wissen entspringt, und welche Gegebenheiten sind es, die wir zu solcher Annahme bedürfen?” (Scheler, 1913: 118).

$8 \quad$ Así lo sostiene Scheler: "Sowohl die Theorie, dass es 'Analogieschlüsse' seien, die dazu führen, bei Wahrnehmung von unseren Ausdruckbewegungen gleichartigen Ausdrucksbewegungen, die wir als Folgen unserer individuellen Ichtätigkeit erleben, auf gleichartige Ichtätigkeiten im Anderen zu schliessen; als die besonders von Th. Lipps vertretene Theorie (...), jene Schwierigkeiten zu lösen. Beide Theorien vermögen ihr Ziel indes nicht zu erreichen" (Scheler 1913: 118s.) Traducción: "Tanto la teoría de la inferencia por analogía, la que se funda a partir de la percepción de nuestros movimientos expresivos, que nosotros vivenciamos a partir de nuestro yoidad individual y que comparamos con la yoidad de los otros, como la particular teoría de Th. Lipps (...), presentan dificultades que hay que superar. Ambas teorías no son capaces, con todo, de alcanzar su meta" (Scheler, 1913: 118ss.). 
La crítica de Scheler sobre la "empatía" (Einfüblung), un tema no menor dentro de la fenomenología, se inicia con un tratamiento histórico de dicha teoría. Se pueden mencionar en este marco los nombres de Wilhelm Perpeet, Friedrich Theodor Vischer, Robert Vischer, Theodor Lipps y Antonin Prandtls. Lipps, por ejemplo, considera que la "percepción sensorial" (sinnliche Wabrnehmung) nos proporciona "cosas" (Dinge), "objetos físicos" (physische Gegenstände), cuerpos y movimientos, los que no son interpretados necesariamente como propios de seres humanos. De ahí, considera Lipps, pertenece al ser humano la "vivencia psíquica" (seelisches Erleben), la que nunca se nos da mediante percepciones sensoriales, sino mediante "percepciones internas" (innere Wabrnebmung); esto es, se nos da como vivencia propia (Michalski, 1997: 81).

La "empatía" (Einfüblung) es, para sus partidarios, una característica de la naturaleza humana, que está compuesta por dos momentos: el instinto de "imitación" (Nachabmung) y el instinto de "manifestación vital" (Lebensäusserung) (Michalski, 1997: 82). La empatía funciona, entonces, de la siguiente manera: yo veo como otro cuerpo se mueve de una manera determinada (por ejemplo, él camina a zancadas) y tiendo a imitarlo, es decir, me muevo de la misma manera (yo camino a zancadas); en esa tendencia al movimiento yace, gracias al instinto de manifestación vital, en una vivencia determinada y propia. Dicho de otra manera, yo "empatizo" (einfüblen) mi vivencia con el cuerpo visto; yo, por decirlo así, "penetro" en el otro, de tal manera que lo que yo siento al andar a zancadas, me ayuda para saber lo que siente el otro cuando anda a zancadas?.

Por otro lado, probablemente fueron desconocidos, para Scheler, los manuscritos de Edmund Husserl sobre la "empatía" (Einfüblung), que hoy conocemos a través del segundo volumen de las Ideas. Con todo, uno también puede suponer que Scheler conocía perfectamente la atmósfera, en la que se desarrollaron las cavilaciones de Husserl sobre la empatía.

Hechas estas aclaraciones históricas, me concentraré en la presentación de los dos argumentos de Scheler contra la teoría de la empatía. Scheler sostiene, en primer lugar, que la teoría de la empatía nos da "una hipótesis sobre el procedimiento, mediante el cual alcanzamos una suposición. Pero nunca es capaz de asegurarnos los fundamentos de esa suposición"

El Historisches Wörterbuch der Philosophie define la empatía de la siguiente manera: "Según Th. Lipps la empatía es la fuente del conocimiento sobre los otros, de tal modo que se desarrollan vivencias de sentimientos percibidas mediante co-ejecuciones (Mitvollzug) motoras, las que, entonces, en un acto de objetivación son atribuidas al otro como su intención o condición” (Ritter, 1972: 396). 
(Scheler, 1913: 120) ${ }^{10}$. En otras palabras, la doctrina de la empatía sería incapaz de diferenciar aquellos "círculos de casos" (Kreise von Fällen), donde involuntariamente un yo o un alma empatizan. Dicho en términos más sencillos, la teoría de la empatía, para Scheler, no es capaz de separar "la fuente del conocimiento de la existencia del yo ajeno de la pura empatía estética del yo, por ejemplo, en un retrato, o de Hamlet, del gesto corporal de un actor". Y, a continuación, comenta agudamente Scheler: "Precisamente aquí no hay nada que decir, respecto de qué dato del proceso de la "empatía" debe coincidir con el propio yo" (Scheler, 1913: 120ss.) ${ }^{11}$. Uno podría decir, argumenta Scheler, que serían necesarios contenidos ópticos de movimientos de expresión o, por lo menos, modos de comportamiento de una esencia viva. Pero ello es, a su juicio, una respuesta insuficiente:

¡Que imágenes ópticas de algún movimiento, son imágenes de movimientos de expresión, es un criterio, el cual supone del mismo modo el conocimiento del fundamento de un algo ajeno y animado! Su interpretación como "expresión" no es el fundamento, sino la consecuencia de esa suposición (Scheler, 1913: 121) $)^{12}$.

Con este lapidario juicio, Scheler sentencia su primera crítica a la teoría de la empatía.

La segunda crítica de Scheler a la teoría de la empatía es la siguiente: "Finalmente la teoría de la empatía no lleva al contenido de la suposición de la existencia de yo ajeno, a saber, de yo ajeno individual" (Scheler, 1913: 121 s. $)^{13}$. Dicha teoría sería capaz sólo de sustentar la creencia según la cual mi yo yacería allí "una vez más". Sin embargo, ella nunca sería capaz de sustentar este yo como ajeno u otro. En otras palabras, la teoría de la empatía sólo logra explicar la ilusión en que sucumbimos cuando uno cree que una parte mía, de mi yo, se encuentra en el yo ajeno (Michalski, 1997:

10 "Was sie gibt, ist eine Hypothese über den Hergang, auf den es zu dieser Annahme kommt. Aber niemals vermag sie uns des Rechtes dieser Annahme zu versichern." (Scheler, 1913: 120).

11 “[...] auch vermag die Theorie nicht die Einfühlung als Erkenntnisquelle der Existenz fremder Iche von der bloss ästhetischen Einfühlung des Ich zu scheiden, z.B. in ein Porträt, oder des Hamlet, dieser Person der künstlerischen Welt, in den Körpergestus eines Schauspielers. Es ist eben hier gar nicht zu sagen, auf welches Datum hin der Prozess der „Einfühlung“ des eigenen Ich stattfinden soll“ (Scheler, 1913: 120ss.). 12 "Dass die optischen Bilder irgendwelcher Bewegungen Bilder von Ausdruckbewegungen sind, das ist eine Einsicht, welche die Kenntnis des Bestandes eines fremden beseelten Etwas eben bereits voraussetzt! Ihre Auffasung als „Ausdruck“ ist nicht der Grund, sondern die Folge dieser Annahme“ (Scheler, 1913: 121).

13 "Endlich führt auch die Einfühlungstheorie nicht zum Inhalt jener Annahme, der Existenz fremder Iche, und zwar zu der fremder Ichindividuen“(Scheler, 1913: 121ss.). 
85). La objeción de Scheler apunta, entonces, a discutir el supuesto de Lipps, según el cual, el yo empático sería una "proyección" (Projektion), un "reflejo" (Spiegelung) o una especie de "irradiación" (Strablung) de mi propio yo en la aparición sensorial de un cuerpo ajeno. No hay para Scheler "duplicado" (Verdoppelung) ni "copia” (Vervielfältigung) de mi propio yo posible. A partir de lo anterior, Scheler sustenta la siguiente tesis: sólo porque nosotros sabemos, que el yo ajeno es un individuo, "nosotros sabemos, que es un 'otro'; esto no es al revés, es decir, que es un individuo, porque es un 'otro"' (Scheler, 1913: 122) ${ }^{14}$. Luego el saber de individuos ajenos incluye no sólo el saber que ellos poseen una determinada corporalidad, sino, sobre todo, el saber que "nosotros nunca adecuadamente podemos comprenderlos en su peculiar e individual esencia" (Scheler, 1913: 122) ${ }^{15}$.

En consecuencia, la crítica de Scheler a la teoría de la empatía alcanza una conclusión negativa: "Ella no es capaz de explicar razonablemente la existencia del otro ajeno o extraño. Por ende, la alternativa scheleriana es recurrir a la fenomenología para encontrar solución a este problema. "Dejémoslas aparte seriamente $y$, en general, todas las suposiciones realistas y practiquemos la fenomenología pura" (Scheler, 1913: 125) ${ }^{16}$.

Así, Scheler considera que las vivencias son sencillamente "dadas" (gegeben), sin necesariamente tener que ser calificadas como propias o ajenas.

No acontece, como supone por ejemplo la teoría de la empatía, que a partir de un material dado "en primera instancia" (zunächst), nuestras vivencias propias nos hayan formado imágenes de vivencias ajenas, sino que una corriente indiferente de vivencias fluye en primera instancia allí, la que contiene tanto vivencias propias como ajenas de modo inseparable y mezcladas unas con las otras; y en esa corriente se forman gradualmente firmes y configurados remolinos, los que remolcan siempre lentamente nuevos elementos de la corriente en su círculo (Scheler, 1913: 127) ${ }^{17}$.

O como sostiene más adelante:

14 "[...] und nur darum wissen wir, das es ein ,anderes“ ist; nicht aber ist es uns ein Individuum, weil es ein ,anderes“ ist!“ (Scheler, 1913: 122).

15 "[...] dass wir diese niemals adäquat, in ihrem eigentümlichen individuellen Wesen, erfassen können“" (Scheler, 1913: 122).

16 "Lassen wir sie aber ernsthaft beiseite und überhaupt alle realistischen Voraussetzungen, und treiben wir pure Phänomenologie“ (Scheler, 1913: 125).

17 "[...]sondern ein indifferenter Strom der Erlebnisse fliesst ,zunächst“ dahin, der Eigenes und Fremdes ungeschieden und ineinandergemischt enthält; und in diesem Strome bilden sich erst allmählich fester gestaltete Wirbel, die langsam immer neue Elemente des Stromes in ihre Kreise ziehen“" (Scheler, 1913: 127). 
"En primera instancia" vive el ser humano más en los otros que en sí mismo; más en la comunidad que en su propio individuo. Son una prueba de ello tanto los hechos de la vida infantil como los hechos de toda vida anímica primitiva del pueblo (Scheler, 1913: 127) ${ }^{18}$.

En esta cita Scheler se distancia definitivamente de una concepción de la empatía al estilo de una egología monadológica —en el sentido que Husserl expondrá posteriormente en la V. Meditación Cartesiana-; en otras palabras, supera la concepción, según la cual dos mónadas son las que desarrollan el proceso intersubjetivo. Para Scheler, salimos de nosotros mismos para, por decirlo así, reconocernos en el otro. Dicho de otra manera, la vida afectiva intersubjetiva se funda, para Scheler, en la simpatía (Sympathie o Mitgefüh). Él ejemplifica su tesis aludiendo a las vivencias de la vida infantil, las cuales se construyen habitualmente en relación con los padres, el entorno, los parientes, los hermanos mayores, la ciudad natal, el país de origen, etc.

De este modo, abordaré a continuación la manera en que Edith Stein tematiza la empatía en su tesis de doctorado en filosofía.

\section{LA EMPATÍA PARA EDITH STEIN}

El texto de Edith Stein Sobre el problema de la empatía tiene una estructura y un estilo propio de una tesis de doctorado alemana, lo que facilita la lectura y la identificación de las problemáticas en su interior. En dicha tesis, Stein profundiza en la idea de Husserl acerca de la empatía como experiencia de la conciencia ajena. Su marco metodológico se estructura, cuando menos en el comienzo del texto, siguiendo las orientaciones de la fenomenología y de los conceptos fundamentales de su maestro: percepción interna/percepción externa, reflexión, intencionalidad, etc. (Infante, 2013: 144). Así, desde las primeras páginas de la tesis de Stein queda planteado el problema relativo a la empatía: "En la base de toda controversia sobre la empatía subyace un presupuesto tácito: nos están dados sujetos ajenos y sus vivencias" (Stein, 2005: 79). Stein comienza su tesis describiendo la empatía en comparación con otros actos, por ejemplo, con el recuerdo, la espera y la fantasía ${ }^{19}$. Es en este contexto donde ella plantea

18 “"Zunächst" lebt der Mensch mehr in den Anderen als in sich selbst; mehr in der Gemeinschaft als in seinem Individuum“ (Scheler, 1913: 127).

19 En este es clave el carácter originario de la empatía en comparación con las vivencias del recuerdo, la espera o la fantasía. "Originarias son todas las vivencias propias presentes como tales — ¿qué podría ser más originario sino la vivencia misma?-. Pero no todas las vivencias están dándose originariamente, no todas son originarias según su contenido. El recuerdo, la espera, la fantasía tienen su objeto no como propiamente presente ante sí, 
su tesis principal. Cito a Stein:

Asi tenemos, en la empatía, un tipo sui generis de acto experiencial. (...) La empatía que considerábamos y tratábamos de describir es la experiencia de la conciencia ajena en general, sin tener en cuenta de qué tipo es el sujeto que tiene la experiencia y de qué tipo el sujeto cuya conciencia es experimentada (Stein, 2005: 88).

El problema está para Stein en que el discurso filosófico tradicional ha tratado sólo del yo puro, del sujeto del vivenciar, pero no necesariamente del otro. Y ese es uno de los intereses centrales de Stein al abordar el problema de la empatía.

Así aparece la experiencia que un yo en general tiene de otro yo general. Así aprehende el hombre la vida anímica de su prójimo, pero así también, como creyente, el amor, la cólera, el mandamiento de su Dios; y no de modo diferente puede Dios aprehender la vida del hombre" (Stein, 2005: 88).

De esta manera, comienza a esbozar Stein el rendimiento filosófico religioso de la empatía que, como sostuve, no es tomado en consideración por Scheler.

Conviene reforzar la explicación de Stein, a modo de excursus, con las reflexiones de Edmund Husserl relativas a la experiencia de los otros en sus Meditaciones Cartesianas (1931), a la que aludí con anterioridad; si bien es un texto posterior a la tesis de doctorado de Stein, encierra las principales tesis husserlianas sobre los otros que la santa carmelita de seguro conoció. Así, al inicio de la V. Meditación, Husserl se pregunta si la fenomenología no es más que un mero solipsismo trascendental una vez llevada a cabo la epojé; su respuesta es negativa: "Pero, ¿qué sucede entonces con otros ego, que no son por cierto mera representación y mera cosa representada en mí, meras unidades sintéticas de verificación posible en mí, sino, por su propio sentido, precisamente otros" (Husserl, 1986: 149). Husserl reconoce, entonces, el tema del otro como un problema propio de la fenomenología, que él denomina: el problema del para-mí-ahí de los otros (Für-mich-da der Anderen) ${ }^{20}$ o el problema de una teoría trascendental

sino que sólo lo presentifican. (...) Mas el sujeto de la vivencia empatizada -y esta es la novedad fundamental frente al recuerdo, la espera, la fantasía de las propias vivenciasno es el mismo que realiza la empatía, sino otro. Ambos están separados, no ligados como allí por una conciencia de la mismidad, por una continuidad de vivencia" (Stein, 2005: 84ss.).

20 Difiero parcialmente de la traducción de García-Baró, quien traduce el giro alemán "Für-mich-da der Anderen" como el "ahí-para-mí" de los otros. Me parece que lo que busca 
de la experiencia del otro, de la llamada empatía (Einfüblung) ${ }^{21}$. Con todo, el análisis husserliano complejiza la discusión porque relaciona el problema de los otros con el tema del mundo. En otras palabras, para Husserl, el alcance de la teoría de la empatía "co-fundamenta también una teoría trascendental del mundo objetivo, y ello plena y absolutamente, o sea, también respecto de la naturaleza objetiva" (Husserl, 1986: 152). ¿Cómo explica Husserl, entonces, la experiencia del otro? Él lo hace desde el yo o ego mismo. Dicho en términos sencillos, hablar del otro es remitirse a sí mismo. "Lo específicamente mío propio como ego, mi ser concreto como "mónada" puramente en mí mismo y para mí mismo, en mí la esfera clausurada de lo mío propio, abarca, igual que toda otra, también la intencionalidad dirigida a algo ajeno. (...) El "otro" remite, por su sentido constituido, a mí mismo: el otro es reflejo de mí mismo, y, sin embargo, no es propiamente reflejo; es un análogo de mí mismo y, de nuevo, no es, sin embargo, un análogo en el sentido habitual" (Husserl, 1983: 154).

Realizado este necesario excursus vuelvo sobre el texto de Stein, procurando responder brevemente a una pregunta que está abierta: ¿cómo refuta Edith Stein las críticas de Scheler a la empatía? Stein le dedica el parágrafo $\$ 6$ de su tesis que se denomina "Confrontación con la teoría de Scheler sobre la aprehensión de la conciencia ajena.” Stein sostiene que debe "medir" (messen) la empatía con una teoría de la conciencia ajena "que se aparta de todas las reseñadas hasta ahora" (Stein, 2005: 107). Ella en su tesis de doctorado, del mismo modo que Scheler en el Sympathiebuch, pasa revista a las teorías explicativas "modélicas", en ese tiempo, de la relación con la conciencia ajena, es decir, la teoría de la imitación, la teoría de la asociación y la teoría de la inferencia por analogía. Como se dijo, Scheler se diferencia de ellas; pero, a su vez, Stein lo hace de Scheler.

La crítica de Stein se centra en una de los pasajes ya citados del Anexo del Sympathiebuch scheleriano. "Según Scheler", sostiene Stein, "el yo ajeno con su vivencia es percibido igual que el propio (...). En el origen hay "una corriente indiferenciada del vivenciar" desde la que, sólo poco a poco, cristalizan hacia fuera las vivencias "propias" y "ajenas"” (Stein, 2005: 108). El punto central de la crítica de Stein a Scheler estriba, entonces, en que "si se toma en serio su discurso de la corriente indiferenciada de vivencias, no es posible entender cómo se debe llegar a una diferenciación dentro de ella" (Stein, 2005: 109). Más aún, la mencionada idea sche-

expresar Husserl con este término es que los otros se encuentran "ahí delante de mí". Por eso, prefiero la traducción "para-mí-ahî" de los otros.

21 Nuevamente difiero de la traducción de García-Baró, porque él traduce el término alemán "Einfühlung" por "endopatía". 
leriana es para Stein irrealizable, "pues cada vivencia es esencialmente vivencia de un yo, y fenomenalmente tampoco es separable en absoluto de él" (Stein, 2005: 109). En ese sentido "propio" y "ajeno", las vivencias propias y ajenas, pertenecen para Stein a distintos individuos, no a una marea de vivencias, es decir, pertenecen a diferentes sujetos anímicos sustanciales cualitativamente formados. Para Stein, entonces, "estos individuos y sus vivencias deben ser accesibles de la misma manera que la percepción interna" (Stein, 2005: 109).

Otra de las críticas de Stein a Scheler tiene que ver con la diferencia entre reflexión y percepción interna o autopercepción. Según Stein la reflexión sería siempre la versión actual de un vivenciar actual, en cambio la percepción interna puede ser inactual. Lo interesante de la discusión se encuentra en la relación que puede establecerse con la empatía. En consecuencia, para Stein es posible establecer tanto un parentesco como diferencias entre la percepción interna y la empatía. El parentesco es el siguiente:

[...] así como en las vivencias propias percibidas se manifiesta el yo propio, así en las empatizadas se manifiesta el individuo ajeno. Pero también vemos la diferencia: en un caso la presentación de las vivencias constituyes es originaria, en otro caso no-originaria (Stein, 2005: 115).

En otras palabras, para Stein, cuando se vivencia un sentimiento como de otro (por ejemplo, su tristeza por la pérdida de un ser querido), lo tengo dado por un lado como originario, como propio ahora (uno cree en la tristeza del otro por la pérdida de su ser querido), aunque también se vivencia dicho sentimiento como no-originario, esto es, como un sentimiento con el que empatizo aún sabiendo que es ajeno (en último término es su dolor, no mi dolor). Precisamente por el carácter no-originario del vivenciar descrito, es que Stein prefiere hablar más que de una percepción interna, de una "intuición interna. Ésta abarcaría entonces también la presentación no-originaria de las vivencias propias: recuerdo, espera, fantasía" (Stein, 2005: 115).

El planteamiento de Stein sobre la empatía se encuentra en la tercera parte de su tesis denominada "III. La constitución del individuo psicofísico". Stein considera que:

[...] lo que hemos hecho hasta ahora era una descripción de la esencia de los actos de empatía. (...) La mayor tarea, con diferencia, está todavía ante nosotros: el tratamiento de la empatía como problema de constitución, o sea, la solución de la pregunta sobre cómo se constituyen en la conciencia las objetividades de las que hablan las teorías usuales de la empatía, a saber, 
individuo psicofísico, personalidad y semejantes” (Stein, 2005: 117).

En este esfuerzo, Stein quiere dejar sentado, en primer lugar, el yo individual o individuo. Y de este modo lo define Stein:

[...] un objeto unitario en el que la unidad de conciencia de un yo y un cuerpo físico se ayuntan (zussamenschliessen) inseparablemente, por lo que cada uno de ellos adquiere un nuevo carácter; el cuerpo aparece como cuerpo vivo; la conciencia como alma del individuo unitario (Stein, 2005: 137-8).

En otras palabras, Stein está describiendo fenomenológicamente su concepción de la persona humana.

Con todo, ella entiende que el problema de fondo de la empatía es mostrar cómo se constituye para nosotros el individuo ajeno. En otras palabras, le interesa abordar a Stein las relaciones intersubjetivas, la capacidad de comunicación con el otro, en definitiva, la posibilidad de empatizar, que, como espero mostrar más adelante, tiene alcances políticos.

De este modo, al comienzo de su tesis de doctorado, Stein trata detalladamente sobre la empatía misma. La define como una vivencia que:

[...] cuando aparece ante mí de golpe, está ante mí como objeto (vg., la tristeza que "leo en la cara" a otros); pero en tanto que voy tras las tendencias implícitas (intento traerme a dato más claramente de qué humor se encuentra el otro), ella ya no es objeto en sentido propio, sino que me ha transferido hacia dentro de sí; ya no estoy vuelto hacia ella, sino vuelto en ella misma hacia su objeto, estoy cabe su sujeto, en su lugar. Y sólo tras la clarificación lograda en la ejecución, me hace frente ora vez la vivencia como objeto (Stein, 2005: 87).

Un destacado fenomenólogo español, Miguel García-Baró, ha interpretado hace tiempo este pasaje; para él tres son los componentes de la empatía en el pensamiento de Stein: la representación, la inmersión y la síntesis ${ }^{22}$.

Veamos el primero, a) la representación ${ }^{23}$. Toda empatía es una intuición representativa donde hay una vivencia que se enfrenta o se hace presente a mi conciencia. Por ejemplo, "mi hijo vive originariamente su alegría, aunque no reflexione en ella en absoluto. Se sabe alegre. (...) Yo, en

22 La traducción al español habla de: aparición de la vivencia, la explitación plenaria y la objetivación comprehensiva de la vivencia explicitada. Cf. Stein, 2015: 87.

23 García-Baró traduce el término alemán "Vergegenwärtigung" como "re-presentación”, mientras que otros traductores, como Gaos, han preferido la noción de "presentificación". 
cambio, sólo la re-presento" (García-Baró, 1999: 38).

El segundo es b) la inmersión. En este grado segundo, me sumerjo en la vivencia del otro o, dicho de otra manera, me sumerjo en la vivencia de alegría de mi hijo, por cierto, con una intensidad que admite amplísimos márgenes de variación. Siguiendo el ejemplo anterior, la alegría de mi hijo, "no es tan solo el objeto de una intención consciente mía, sino que me ha llevado a sí misma y estoy vuelto al objeto de ella, como lo está el niño. Estoy, por así decir, más que frente a él, junto a él, mirando en su misma dirección, aunque siempre siga haciéndolo con una mirada que es distinta de la suya" (García-Baró, 1999: 42).

Finalmente, el tercer componente de la empatía es la conciencia de la síntesis. Este tercer estadio es regresar a la objetivación del principio de todo el proceso, pero habiendo ganado la explicitación del sentido que ha sido recorrido. Para concluir el ejemplo, "ahora, al vivir esta síntesis final, al regresar de mi viaje por lo reproducido, ya entiendo, ya conozco bien, ya me represento viva y fresca la alegría del niño, tras haberme introducido, por decirlo así, en ella y haber seguido sus propios caminos." (García-Baró, 1999: 43) Con lo anterior, procuro contestar la pregunta acerca de la comprensión que tiene Edith Stein de la empatía.

\section{AlgunOS ALCANCES DEL PENSAMIENTO DE STEIN}

En lo que sigue, quisiera bosquejar algunos rendimientos del pensamiento de Stein sobre la empatía en los ámbitos religioso y político. En el ámbito religioso, me focalizaré en la cuarta parte de su tesis de doctorado. $\mathrm{Al}$ inicio, Stein retoma sus desarrollos previos:

Al yo individual cuya constitución nos ocupó hasta ahora lo considerábamos como miembro de la naturaleza, al cuerpo vivo como un cuerpo físico entre otros, al alma fundada en él como padeciendo y ejerciendo efectos, incorporada a la conexión causal, a todo lo psíquico como un acontecer natural, a la conciencia como una realidad. (...) La conciencia se nos mostraba no sólo como acontecer causalmente condicionado, sino a la vez como constituyendo un objeto, con lo que sale del entramado de la naturaleza y se la coloca enfrente: la conciencia como correlato del mundo de objetos no es naturaleza, sino espíritu (Stein, 2005: 173).

El planteamiento principal de Stein es que el espíritu (a su modo la empatía) constituyen a la persona humana. Para Stein, con cada acto de empatía, esto es, "con cada aprehensión de un acto sentimental, ya hemos penetrado en el reino del espíritu” (Stein, 2005: 174). Pues, así como en los actos de percepción se constituye la naturaleza física, del mismo modo, 
se constituye un nuevo reino de objetos en el sentimiento: el mundo de los valores.

Alcanzado este punto, es posible preguntarse, ¿de qué sirven todas investigaciones que ha desarrollado Stein? Por un lado, hay cuestiones de autoconocimiento y, por otro lado, hay cuestiones de tipo religioso. En el primer caso, sostiene Stein que:

[...] de lo dicho se desprende también qué relevancia tiene el conocimiento de la personalidad ajena para nuestro "autoconocimiento". Como antes vimos, no sólo nos enseña a hacernos a nosotros mismos objeto, sino que lleva a desarrollo, como empatía con "naturalezas semejantes", es decir, con personas de nuestro tipo, lo que "dormita" en nosotros, y como empatía con estructuras personales formadas de otra manera nos ilustra sobre lo que nosotros no somos, sobre lo que somos de más o menos respecto a los demás. Con ello viene dado, a la par que el autoconocimiento, un importante medio auxiliar para la autovaloración (Stein, 2005: 200).

En otras palabras, según Stein, la vivencia del valor es fundante de la valía propia; de ese modo, con los nuevos valores obtenidos en empatía se abre simultáneamente la mirada a valores desconocidos de la persona propia. Por ejemplo, el contacto con personas ajenas a mi familia que estén en situación de vulnerabilidad puede despertar en mí el sentimiento de solidaridad.

Los estudios de Stein tienen también, como se ha dicho, un alcance religioso incipiente. Al final del texto, Stein se pregunta lo siguiente:

¿Pero cómo están las cosas respecto a las personas espirituales puras cuya representación no encierra contradicción alguna? ¿No es pensable ninguna relación entre ellas? Ha habido hombres que creyeron experimentar la acción de la gracia divina en un cambio repentino de su persona. (...) Mientras tanto, cedo a investigaciones ulteriores la respuesta de la pregunta planteada y me conformo aquí con un "non-liquet" (Stein, 2005: 201-2).

Las investigaciones "ulteriores" a las que se refiere Stein son dos: Contribuciones a la fundamentación filosófica de la psicología y de las ciencias del espiritu y Una investigación sobre el estado. En el caso de la primera, particularmente en la sección denominada "Causalidad psíquica", Stein sostiene que la fuerza espiritual del ser humano encuentra su alimento en el mundo de los valores naturales, pero también en Dios y en los otros hombres. En el caso de la segunda, la abordaremos a continuación, desde una perspectiva 
filosófico política ${ }^{24}$.

De este modo, en el texto Contribuciones a la fundamentación filosófica de la psicología y de las ciencias del espiritu, publicado en el año 1922, Edith Stein desarrolla algunas temáticas que dejó sin profundizar en su tesis de doctorado. El texto está divido en dos estudios, uno sobre "Causalidad psíquica", ya mencionado, y otro denominado "Individuo y comunidad". Naturalmente, dado el punto que busco desarrollar, me concentraré en este segundo estudio, en especial, en el apartado $\$ 4$. La relación fundamentante entre individuo y sociedad, letra d) Individuo y comunidad. De este texto quisiera destacar dos ideas: a) ¿Cómo entiende Edith Stein la relación entre individuo y comunidad? y b) ¿Cómo caracteriza Edith Stein a la comunidad? En relación a la primera pregunta, la tesis de Stein es clara: "El individuo no queda realmente absorbido por la vida de la comunidad, y tan sólo en cuanto él vive como miembro de la comunidad, se expresa en su comportamiento el carácter de la comunidad" (Stein, 2005: 471). Este texto de Stein, es precisamente la tesis contraria de Scheler a la que aludíamos anteriormente, según la cual, vive el ser humano más en los otros que en sí mismo; más en la comunidad que en su propio individuo. ¿Cómo refuta Stein estos argumentos schelerianos? Stein propone principalmente distinguir entre el carácter de una comunidad (por ejemplo, de un pueblo) del carácter de los individuos que pertenecen a ella. "El carácter popular (es decir, el carácter típico de los conciudadanos) y el carácter del pueblo (como totalidad) no tienen por qué coincidir enteramente" (Stein, 2005: 471). Ella insiste en que:

[...] hay representantes más o menos típicos de la comunidad, y puede haber también individuos en los que no se aprecie para nada su pertenencia a tal o cual comunidad, que resulten extraños en su propia familia o en su propio pueblo. Pero aun en el caso de que la persona sea la expresión más pura del tipo comunitario, el ser de dicha persona no se agota en esa modalidad (Stein, 2005: 472).

Pertenece a la esencia de la persona humana, según Stein, el no ser

\footnotetext{
24 La elección de estos textos no es arbitraria, puesto que se sustenta, ni más ni menos, que en las pistas que la propia Edith Stein entrega. De este modo, ella sostiene al inicio del primer parágrafo de Una investigación sobre el estado, \$1. La comunidad estatal, que "en otro lugar hemos investigado los distintos tipos de convivencia de los sujetos" (Stein, 2005: 525). Ese otro lugar al que se refiere Stein es el texto Contribuciones a la fundamentación filosófica de la psicología y de las ciencias del espiritu (1922). Es este texto el marco conceptual desde donde desarrolla Stein Una investigación sobre el estado (1922) y es en el mencionado marco conceptual, reitero, Contribuciones a la fundamentación filosófica de la psicología y de las ciencias del espiritu, donde se aprecia la discusión con Max Scheler.
} 
una simple suma de cualidades típicas, sino que "el poseer un núcleo individual que confiera un sello individual incluso a todo rasgo típico de su carácter" (Stein, 2005: 472). Es este "núcleo individual" el que busca diferenciar Stein en contraste con Scheler.

Dicho lo anterior, no es extrañar que Stein posea una concepción de la "comunidad" basada en la persona humana. De este modo, Stein defiende la analogía según la cual un pueblo es semejante a una persona individual. El pueblo, por ejemplo, tiene un "entorno" en los pueblos que quedan dentro de su horizonte e incluso "vida interior" que se expresa en sus vivencias, creaciones, instituciones, etc. Con todo, el tema más importante es que la comunidad se sustenta en una "vida anímica común" (Stein, 2005: 480), en un "carácter comunitario de la vida" (Stein, 2005: 473), en una "disposición originaria común” (Stein, 2005: 473). Lo que busca destacar Stein con estas expresiones es que los individuos no están dirigidos unos hacia otros, sino que se vuelven en común hacia algo objetivo. "Por eso, hemos subrayado determinadas modalidades de volverse unos a otros, y lo hemos hecho únicamente porque pueden fundamentar en un sentido todavía más profundo la vida comunitaria" (Stein, 2005: 478). A partir de lo anterior, no es extraño que Stein hable de un "carácter", de un "alma" y de un "espíritu" de la comunidad.

Así, muy brevemente expuesto, Stein entiende que el "carácter de una comunidad" tiene que ver con los niveles personales en que penetra la vida comunitaria. "Si una comunidad aparece como muy valiosa a los individuos que pertenecen a ella, si los individuos se adhieren a la comunidad, eso dependerá de la configuración del carácter de la comunidad" (Stein, 2005: 481). Por otro lado, habla también Stein de "alma de una comunidad". A pesar de las legítimas aprensiones que puedan manifestarse, ella cree que "lo que efectúa en la comunidad es un estar abiertos los unos hacia los otros, un expansionarse del alma del uno a través del otro y un activarse del alma en acciones comunitarias y en rasgos de carácter de la comunidad que se hayan formado" (Stein, 2005: 482). Por último, por "espíritu de la comunidad", Stein entiende lo siguiente: se trata de una unidad cualitativa, que impregna las manifestaciones vitales de la personalidad individual o de la personalidad colectiva, y que las caracteriza como pertenecientes al ámbito precisamente de esa personalidad. Si el centro de esa configuración unitaria del individuo o de la comunidad reside en tales manifestaciones, entonces les atribuimos un "alma". Poseer alma significa llevar en sí mismo el centro de gravedad de su propio ser" (Stein, 2005: 483).

Para complementar estas ideas, me referiré al parágrafo \$1. La comunidad estatal, letra c) Estado y Pueblo de Una investigación sobre el estado. La pregunta que orienta el trabajo de Stein, me parece, es la siguiente: ¿en qué 
se sustenta la relación entre los individuos en el estado? La respuesta habitual sería jurídica: en los derechos y deberes que se da una sociedad. Con todo, la respuesta de Stein es, por otro lado, filosófica: la relación entre los individuos en el estado se sustenta en un centro espiritual.

No es la estructura del Estado sino la estructura de las personas espirituales la que permite explicar (...) el que una entidad estatal concreta se alce sobre el fundamento de una comunidad existente, y el que por otra parte, enlace con un vínculo comunitario a las personas abarcadas por ella (Stein, 2005: 539).

¿Qué es lo que produce dicho vínculo? Para Stein, la cultura. "Una comunidad con la amplitud y la plasticidad de un pueblo sólo se lo puede tomar como comunidad de pueblo si y sólo si de su espíritu nace una cultura propia, determinada por su carácter específico" (Stein, 2005: 541). En consecuencia, todas las expresiones culturales como las obras de arte, de la ciencia o de formas de vida estilizadas, remiten "a un centro espiritual que constituye su origen; y ese centro es una comunidad creativa, cuya peculiaridad anímica específica repercute y se refleja a través de todas sus producciones" (Stein, 2005: 541). Por tanto, para Edith Stein, el Estado no debiera estar fundado en las estructuras jurídicas o normativas, sino que en algo más profundo, esto es, en este fondo del ser del pueblo que es este centro espiritual de la cultura ya descrito.

\section{PALABRAS FINALES}

El problema de la empatía es un problema tremendamente actual. Su intensidad puede ir desde un plano tan trivial como el dolor de muelas de mi amigo, la alegría de mi mujer o el dolor que vive un desconocido por la muerte de un familiar. El tema de la empatía nos permite explicar, entonces, las relaciones con nuestros semejantes. Es, en definitiva, una invitación a ponernos en el lugar del otro. Esta problemática que parece tan teórica está siendo utilizada para ámbitos tan disímiles como el de la salud o el religioso. En el ámbito de la salud, la empatía es crucial en la formación de los profesionales de dicha área, en particular, porque los temas del cuidado del enfermo exigen a los equipos de salud ponerse en su lugar. En el plano religioso, tiene que ver con el acompañamiento de las penas y alegrías, los dolores y los goces de nuestros semejantes. En ese plano, es muy interesante el aporte de Edith Stein, que puede sintetizarse de la siguiente forma:

a) Para Edith Stein el ser humano no se comprende sino como un 
ser espiritual, capaz de salir de sí, de trascenderse. Y este trascenderse es algo fundamental para el desarrollo de su ser, tanto de cara a conocer el mundo, el otro, como para conocerse a sí mismo.

b) El ejercicio de la empatía es fundamental para que el ser humano reconozca a los otros como "sujetos" de experiencia y no como meros objetos y que, por ende, también aprende del contacto con los otros.

c) En definitiva, el problema que le interesa resolver a Edith Stein es el de la persona como sujeto espiritual.

Por otro lado, hay también en el pensamiento de Stein, un intento de aportar una visión distinta de las relaciones políticas, no centradas exclusivamente en los ámbitos normativos o contractuales, sino que en otra dimensión más profunda: el espíritu. Quisiera sintetizar, en el aspecto político, algunas de las ganancias de los textos ya revisados. Las principales son:

a) Las tesis de Scheler: hay una corriente de vivencias y el individuo vive más en la comunidad o en los otros que en sí mismo.

b) El contraargumento de Stein: el ser de la persona no se agota en esa modalidad.

c) La caracterización de la comunidad a partir de elementos individuales: carácter, alma y espíritu.

d) La existencia de un centro de gravedad en la comunidad: el espíritu.

e) El fundamento del estado: centro espiritual.

\section{REFERENCIAS}

-Bornemark, J. (2010). Max Scheler and Edith Stein as precursors to the "turn to religion" within Phenomenology. Phenomenology an Religion: New Frontiers. Hüddinge: Estocolmo.

-Crespo, M. (Inédito). Husserl versus Scheler. Dos visiones acerca de la experiencia ajena. -Ferrater Mora, J. (1999). Diccionario de Filosofía. Ariel: Barcelona.

-García-Baró, M. (1999). Vida y mundo: la práctica de la fenomenología. Trotta: Madrid. -Husserl, E. (1983). Meditaciones cartesianas. Fondo de Cultura Económica: México. -Infante, F. (2013). Ficción en la idea de empatía de Edith Stein. Ideas y valores, LXII(153), 137-155.

-Michalski, M. (1997). Fremdwahrnehmung und Mitsein. Zur Grundlegung der Sozialphilosphie im Denken Max Schelers und Martin Heideggers. Bouvier: Bonn.

-Moran, D. (2004). The problem of empathy: Lipps, Scheler, Husserl and Stein. Amor amicitiae: on the love that is friendship. Recherches de Théologie et Philosophie médiévales. Peeters: Leuven. 
-Muñoz, E. (2011). Planteamientos ante la intersubjetividad: el Sympathiebuch de Max Scheler y su repercusión en Sery Tiempo de Martin Heidegger. Alpha, (32), 199-214.

-Muñoz, E. (2013). Heidegger y Scheler: estudios sobre una relación olvidada. Cuadernos de Anuario Filosófico. Pamplona: Universidad de Navarra.

-Ritter, J. (1972). Historisches Wörterbuch der Philosophie (Vol. II). Schwabe \& Co.: Stuttgart.

-Scheler, M. (1913). Zur Phänomenologie und Theorie der Sympathiegefüble und von Liebe und Hass. Mit einem Anhang über den Grund zur Annabme der Existenz des fremdes Ich. Max Niemeyer: Halle a.S.

-Sepp, H.-R. (1998). La postura de Edith Stein dentro del movimiento fenomenológico. Anuario filosófico, (31), 709-729.

-Stein, E. (2005). Obras completas. Monte Carmelo: Madrid.

-Zahavi, D. (2010). Empathy, Embodiment and Interpersonal Understanding: From Lipps to Schutz. Inquiry, 53(3), 285-306.

-Zordan, P. (2005). Edith Stein e Max Scheler. Un confronto a partire dalle analisi del problema dell' empatia. Segni e Compresione, XIX(54), 64-78.

Sumario: Introducción; 1. La empatía para Max Scheler; 2. La empatía para Edith Stein; 3. Algunos alcances del pensamiento de Stein; 4. Palabras finales; Referencias. 